\title{
Farklı IBA uygulamalarının Corylus colurna L.'nın odun çelikleriyle köklenmesi üzerine etkisi
}

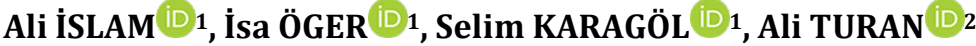 \\ 10rdu Universitesi, Ziraat Fakültesi, Bahçe Bitkileri Bölümü, Ordu \\ ${ }^{2}$ Giresun Üniversitesi, Giresun MYO, Fındık Eksperliği Bölümü, Giresun
}

Alınış tarihi: 5 Aralık 2019, Kabul tarihi: 30 Aralık 2019

Sorumlu yazar: Ali İSLAM, e-posta: islamali@hotmail.com

\section{Öz}

Bu çalışmada Türk findığı olarak bilinen Corylus colurna'nın odun çelikleri kullanılmıştır. Çelikler 15 Aralık tarihinde alınmış olup kontrol, 1000 ppm, 2000 ppm, 4000 ppm ve 8000 ppm olarak hazırlanan IBA çözeltisi ile muamele edilmiştir. Her uygulama için 3 tekerrür olacak şekilde her tekerrürde 20 çelik toplamda 300 çelik kullanılmıştır. Çelikler ısıtma ve mistleme bulunan ortama dikilmişlerdir. 90 gün sonra çelikler çıkarılmıştır. Canlı olmayan çelik sayısı, canlı çelik sayısı, köklenen çelik sayısı, kallus oluşturmuş çelik sayısı, kök sayısı ve kök uzunluğu belirlenmiştir. Buna göre en yüksek canlı çelik oranı ve köklenen çelik sayısı IBA 4000 ppm dozundan elde edilmiştir. Çeliklerde en yüksek ortalama kök sayısı 8000 ppm uygulamasında 4.83 olarak bulunmuştur. Ey yüksek köklenme oranı 4000 ppm uygulamasından (\%21.7) elde edilmiștir. $\mathrm{Bu}$ araștırmanın sonucu olarak tüm bulgular dikkate alındığında Corylus colurna odun çeliklerinin köklenmesinde 4000 ve 8000 ppm IBA önerilir.

Anahtar kelimeler: Türk findığı, Corylus colurna, köklenme, IBA

Effect of different IBA applications on rooting of Corylus colurna $\mathrm{L}$.

\author{
Abstract \\ This study was carried out in the hardwood cuttings \\ of Corylus colurna known as Turkish hazelnut. The \\ cutting were taken on December 15 and it was \\ treated with IBA solution prepared at $0 \mathrm{ppm}$ (as
}

control), 1000 ppm, 2000 ppm, 4000 ppm and 8000 ppm, 3 replications were used for each application, totaling 300 cuttings. The hardwood cuttings were planted with heat and mist. After 90 days it were removed. The number of live cutting, rooted cutting, callus formation, number of roots and root length were determined. Accordingly, the highest live cutting rate and the number of roots were obtained from the $4000 \mathrm{ppm}$ dose of IBA. The highest average root number in the cuttings was found 4.83 in 8000 ppm application. The high rooting rate was obtained by $4000 \mathrm{ppm}(21.7 \%)$. Considering all the findings as a result of this research, 4000 and 8000 ppm IBA are recommended for the rooting of Corylus colurna hardwood

Key words: Turkish hazelnut, Corylus colurna, rooting, IBA

\section{Giriş}

Türkiye son yıllar ortalaması olarak 650 bin ton üretim ve 705 bin ha alan ile dünyanın en önemli fındık üreticisidir. Dünya fındık üretiminin \% 70 ini Türkiye karşılamaktadır (İslam ve ark. 2018). Türkiye'nin tarım ürünleri ihracatının yaklaşık \% 20'sini fındık teşkil etmektedir. Özellikle Doğu Karadeniz Bölgesi mevcut ekolojisi dolayısıyla findık tarımına çok uygundur. Bu bölge findığın anavatanı ve kültür tarihinin başlangıç yeri olarak kabul edilmektedir. Dolayısıyla geleneksel bir yetiștiricilik süregelmiştir. Fındık Doğu Karadeniz kıyı şeridi boyunca tarım ürünleri içerisinde ana ürün olarak bulunmakta ve yetiştiricilikte Tombul, Palaz, Çakıldak, Foşa ve Mincane çeşitleri yaygın olarak kullanılmaktadır (İslam, 2018). Ülkemizde yaygın 
yetiştirilen fındık türü Corylus avellana'dır. Corylus colurna ise anavatanı ülkemiz olan ve Türk fındığı" olarak bilinen, Kuzey Anadolu'da yaygın olarak yetișen önemli bir türdür (Ayan ve ark. 2016).

Ülkemizde zengin bir meyvecilik kültürü yanında meyve fidanı üretiminde de önemli gelişmeler kaydedilmiştir. Türkiye meyve ve bağ fidanı üretimi 238 milyon adettir (TÜIK, 2016). Fidan üretim ve dağıtım kayıtlarında fındık fidanı üretimi bulunmamaktadır. Findıkta fidanların nasıl ve nereden temin edildiği konusunda yapılan bir çalışmada yeni bahçe tesislerinde kullanılan fidanların tamamının (\%100) dip sürgünlerinden elde edildiği belirtilmiştir. Üreticiler fidan olabilecek dip sürgünlerinin seçiminde bol ürün veren ocakları tercih etmekte, bol köklü, iyi gelişmiş ve sağlıklı fidanları kullanmaktadırlar. Bahçe tesisinde kullanılan fidanların \%59.58'inin üreticilerin kendi bahçelerinden, \% 27.92'sinin çevredeki diğer bahçelerden, \% 8.17'sinin il dışından ve \% 3.50'sinin de tarım teşkilatlarından sağlandağı da belirtilmiştir (İslam, 2001).

Arıkan (1963) findık yetiştirme tekniğinde en kolay fidan üretme yolunun dip sürgünü (piç) ile olduğunu ve fidan olarak kullanılacak dip sürgünlerinin düzgün ve hastalıksız, dipten yeni sürgünleri sürmemiş, 1-2 yaşında, ocağın çevresinde sürmüş fışkınlardan, bol köklü ve zedelenmemiş sağlıklı bitkilerden oluşması gerektiğini kaydetmiştir. Yeni bahçe kurarken kullanılacak fidanların seçiminde iyi gelişmiş ve bol ürün veren ocaklardan alınmasına dikkat edilse bile, elde edilen findık fidanları genellikle zayıf köklü olmaktadır.

Ülkemizde findıkta büyük çoğunlukla ocak usulünde tesis edilen bahçelerde yetiștiricilik yapılmaktadır. ABD, İspanya ve Şili gibi ülkelerde ise tek gövdeli yetiştiricilik sözkonusudur (Karatas ve ark. 2018). Bazı ülkelerde dip sürgünü üretmeyen Corylus colurna'dan elde edilen Dundee, Newberg, Gasaway anaçları kullanılmaktadır. Ekonomik bir çoğaltma yöntemi olarak tepe daldırması ile elde edilen fidanlar yeni bahçe tesisinde kullanılmaktadır. Fındıkta anaç ve fidan üretimi konusunda dünyada yapılmış pekçok çalışma bulunmaktadır (Lagerstedt, 1976 ve 1993; Gautam ve Howard, 1994Yu ve Reed, 1995: Korac ve ark., 1997; Bassil ve ark. 1991; Achim ve ark., 2000; Damiano ve ark. 2005; Roversi, 2015).

Kantarcı ve Ayfer (1992) C. avellana da yaptığı çalışmada yüksek dozda IBA (5000 ppm) uygulamasının köklenme oranını arttırdığını bildirmiştir. IBA uygulamasının yapıldığı birçok çalışmada kimyasal uygulama ile birlikte çeliklerin alım zamanlarına da bakılmış olup IBA uygulamasının çeliğin alınma tarihinden bağımsız olarak kök sayısını ve kök kalitesini önemli ölçüde arttırdığı saptanmıştır (Ughini ve Roversi 2005; Kantarcl ve Ayfer 1992). Hartmann ve Kester (1990) de fındıkta odun çelikleri ile çoğaltmada başarı için yüksek konsantrasyonların kullanılması gerektiğini ifade etmişlerdir. Ercisli ve Read (2001) findığın yumuşak ve yarı odunsu çeliklerle yaptıkları köklendirme çalışmalarında, 2000 ppm IBA dozunda yüksek köklenme elde etmişlerdir.

Meyvecilik fidan üretimi ile başlar. Fidanın da ismine doğru, sağlıklı ve standartlara uygun olması gerekmektedir. Fidancllıta vejetatif çoğaltma yöntemleri öne çıkmaktadır. Bu çalışmanın amacı da fındık için anaç olarak kullanılan Corylus colurna türünde odun çelikleri kullanılarak köklenme için uygun IBA konsantrasyonunu belirlemektir.

\section{Materyal ve Metot}

Araştırmanın materyali Erfelek (Sinop) ve Terme (Samsun) ilçelerindeki orman arazilerinden temin edilen $C$. colurna bitkileridir. Türk findığına ait odun çelikleri 15 Aralık 2017 tarihinde temin edilmiştir. Alınan çelikler $+4^{\circ} \mathrm{C}$ sıcaklık ve $\% 90$ nemde, kontrollü depo ortamında 30 gün süre ile bekletilmiştir. Köklendirilecek çeliklere uygulanacak olan IBA dozları Ordu Üniversitesi laboratuarlarında 27 Ocak 2018 tarihinde 0 (kontrol), 1000ppm, $2000 \mathrm{ppm}, \quad 4000 \mathrm{ppm}$ ve $8000 \mathrm{ppm}$ olarak hazırlanmıştır. Çelikler 5-6 saniye IBA çözeltilerine daldırılmıştır (Hartman ve Kester, 1990). 28 Ocak 2018 tarihinde hormon uygulamalarma tabii tutulan çelikler $20-24^{\circ} \mathrm{C}^{\prime}$ ye ayarlanmış alttan ısıtma ve mistleme ünitesine sahip yüksek tünelde perlit ortamına 3'te 2'si gömülerek 90 gün süre ile köklenmeye alınmıştır. 90 gün sonunda sökülen çeliklerde canlı olmayan çelik sayısı, canlı çelik sayısı, köklenen çelik sayısı, kallus oluşturmuş çelik sayısı, kök sayısı ve kök uzunluğu belirlenmiştir.

Araştırma tesadüf parselleri deneme deseni ile kurulmuş olup istatistik analizler için JMP 10.0 istatistik paket programı kullanılmış, ortalamalar Tukey çoklu karşılaştırma testi ile karşılaştırılmıştır. Kontrol uygulaması ile birlikte 3 tekerrür olacak şekilde her tekerrürde 20 çelik toplamda 300 çelik kullanılmıştır.

\section{Bulgular ve Tartışma}

Corylus colurna'nın köklenmesi ile ilgili elde edilen sonuçlar Çizelge 1 ve 2'de sunulmuştur. En yüksek 
canlı çelik ve köklenen çelik sayısı IBA 4000 ppm dozundan elde edilmiştir. Bu durumda en yüksek köklenme oranı \% 21.7 ile 4000 ppm dozundan elde edilirken kontrolde köklenme olmamıștır. Srivastava ve ark. (2010) 3000 ppm dozunda \%33 köklenme elde etmişlerdir. Hartmann ve Kester da (1990) findıkta odun çelikleri ile çoğaltmada yüksek IBA dozlarını önermektedir.

Çizelge 1. Corylus colurna'da canlı çelik sayısı, canlı olmayan çelik sayısı, kallüs oluşturan çelik sayısı, köklenen çelik sayısı ve yüzdesi değerleri

\begin{tabular}{cccccc}
\hline Uygulama & Canlı Çelik sayısı & $\begin{array}{c}\text { Canlı olmayan } \\
\text { çelik sayısı }\end{array}$ & $\begin{array}{c}\text { Kalluslenen çelik } \\
\text { sayısı }\end{array}$ & $\begin{array}{c}\text { Köklenen çelik } \\
\text { sayısı }\end{array}$ & $\begin{array}{c}\text { Köklenen çelik } \\
\text { yüzdesi (\%) }\end{array}$ \\
\hline Kontrol & 22 & 38 & 12 & $0 \mathrm{~d}$ & $0.0 \mathrm{~d}$ \\
$1000 \mathrm{ppm}$ & 23 & 37 & 12 & $8 \mathrm{~b}$ & $13.3 \mathrm{~b}$ \\
$2000 \mathrm{ppm}$ & 24 & 36 & 19 & $4 \mathrm{c}$ & $6.7 \mathrm{c}$ \\
$4000 \mathrm{ppm}$ & 28 & 32 & 15 & $13 \mathrm{a}$ & $21.7 \mathrm{a}$ \\
$8000 \mathrm{ppm}$ & 17 & 48 & 9 & $5 \mathrm{c}$ & $8.3 \mathrm{c}$ \\
\hline
\end{tabular}

*: aynı harfle gösterilen ortalamalar arasında fark yoktur $(\mathrm{p}<0.05)$

Çizelge 2. Köklenen çeliklerde kök sayısı ve kök uzunluğu değerleri

\begin{tabular}{ccc}
\hline Uygulama & $\begin{array}{c}\text { Çelik başına ortalama } \\
\text { kök sayısı }\end{array}$ & $\begin{array}{c}\text { Çelik başına ortalama } \\
\text { kök uzunluğ }(\mathrm{cm})^{*}\end{array}$ \\
\hline Kontrol & $0.00 \mathrm{~b}$ & $0.00 \mathrm{~b}$ \\
$1000 \mathrm{ppm}$ & $3.27 \mathrm{ab}$ & $3.40 \mathrm{ab}$ \\
$2000 \mathrm{ppm}$ & $3.33 \mathrm{ab}$ & $5.33 \mathrm{a}$ \\
$4000 \mathrm{ppm}$ & $3.66 \mathrm{ab}$ & $4.93 \mathrm{ab}$ \\
$8000 \mathrm{ppm}$ & $4.83 \mathrm{a}$ & $7.60 \mathrm{a}$ \\
\hline
\end{tabular}

*: aynı harfle gösterilen ortalamalar arasında fark yoktur $(\mathrm{p}<0.05)$

Araștırmada kontrolde köklenme olmamıș, bitki bașına ortalama kök sayısı 8000 ppm uygulamasında 4.83 olarak bulunmuștur.

IBA uygulamaları arasında $8000 \mathrm{ppm}$ uygulanmış çeliklerde, köklenen bitki başına kök sayısı diğer dozlara göre önemli düzeyde yüksek bulunmuștur. 1000,2000 ve 4000 ppm uygulamalarindan elde edilen sonuçlar istatistiki olarak benzer olup kontrolden farklıdır.

Kantarcı ve Ayfer (1992) C. avellana türünde yaptığ çalışmada yüksek dozda IBA $(5000 \quad$ ppm $)$ uygulamasının köklenme oranını arttığını, Erdoğan ve Smith (2005) ise ortalama kök sayısı bakımından bizim bulgularımız ile benzer sonuçlar elde etmişlerdir.

Köklenme amacıyla IBA uygulamasının yapıldı̆̆ı birçok çalıșmada, uygulama ile çelik alma zamanlarının köklenmeye etkisi incelenmiș olup IBA uygulamasının çeliğin alınma tarihinden bağımsız olarak kök sayısını ve kök kalitesini önemli ölçüde artırdığı görülmüştür (Ughini ve Roversi, 2005; Kantarcl ve Ayfer, 1992).

\section{Sonuç}

Corylus colurna'nın odun çeliklerinin köklenmesi üzerine IBA uygulamalarının etkisinin incelendiği bu çalışmada en yüksek köklenme oranı 4000 ppm IBA uygulamasından (\%21.7) elde edilmiştir. Kontrol grubunda köklenme olmamıştır. En yüksek ortalama kök sayısı ve kök uzunluğu ise 8000 ppm dozlarına aittir.

Elde edilen sonuçlara göre Türk findığında dinlenme döneminde alınan odun çeliklerinin köklenmesinde köklenme yüzdesi bakımından 4000 ppm, kök sayısı bakımından 8000 ppm IBA dozu önerilebilir. Çalıșmanın daha ayrıntılı olarak farklı köklenme hormonları kullanılarak, farklı zamanlarda, farklı çelik tipleri ile devam ettirilmesi önerilmektedir.

\section{Kaynaklar}

Arıkan, F., 1963. Fındık Ziraatının Gelișme İmkânları. Tarım Bakanlığı Mesleki Kitaplar Serisi, Güzel Sanatlar Matbaası, Ankara, 64 s.

Ayan, S., Ünalan, E., Yer, E.N., Sakıcı, O. E., İslam, A. 2016. Population diversity in Northwest Anatolia Forests in terms of nut characteristics of Turkish hazelnut (Corylus colurna L.) (Kastamonu province), International Multidisciplinary Congress of Eurosia, 11-13 July, 2016, Odesa, Ukraine.

Bassil, N.V., Proebsting, W.M., Moore, L.W., Lightfoot, D.A. 1991. Propagation of hazelnut stem cuttings using Agrobacterium rhizogenes. HortScience 26:10581060

Damiano, C., Catecaro, E., Giovinazzi, J., Frattarelli, A., Caboni, E. 2005. Micropropagation of hazelnut (Corylus avellana L.) Acta Hort. 686:221-226. 
Ercisli, S., Read, P.E. 2001. Propagation of hazelnut by softwood and semi-hardwood cuttings under Nebraska conditions. Acta horticulturae 556(556):275-279.

Erdogan, V, Smith, DC. 2005. Effect of tissue removal and hormone application on rooting of hazelnut layers. HortScience 40: 1457-1460.

Gautam, D.R., Howard, B.H. 1994. Influence of preconditioning treatments and propagation environments of the rooting of hazelnut leafy stem cuttings. Acta Hort. (ISHS) 35:361-369.

Hartmann, H.T., Kester D.E. 1990. Plant Propagation. Principles and Practices, 4th Ed DOI: $10.2307 / 2483997$

İslam, A. 2001. Türkiye Fındık Yetiştiriciliğinde Fidan Kullanımı. I. Ulusal Fidancilık Sempozyumu, http://www.agr.ege.edu.tr/ fitekno

İslam, A. 2018. Hazelnut culture in Turkey. Akademik Ziraat Dergisi, 7(2), 259-266.

İslam, A., Cristofori, V., Rovira, M. 2018. Hazelnut growing in Europe. MKB Yay. Ordu.

Kantarcl, M., Ayfer, M. 1992. Propagation of Some Important Turkısh Hazelnut Varıetıes By Cuttıngs. Acta Horticulturae 351: 353-360.

Karatas Yavuz, S., İslam, A., Tonkaz, T., Özkutlu, F., Rovira, M., Romero, A., Cristofori, V., Silvestri, C., Speranza, S., Cetin, S. 2018. Examination of modern and traditional applications in hazelnut production. Acta horticulturae 1226: 329-332.

Korac, M., Ninictodorovic, J., Cerovic, S., Golosin, B., 1997. Results of Hazel Grafting on Turkish Filbert. IV. Acta Horticulture 445:419-422Achim ve ark., 2000;

Lagerstedt, H. 1993. The evolution of a clonal filbert rootstock. Proceedings of the Nut Growers Association of Oregon, Washington and British Columbia 78, 89-101.

Lagerstedt, HB. 1976. Development of Rootstock for Filberts. Annu Rep Northern Nut Growers Assoc 65:161-165.

Roversi, A., 2015. How to Propagate no Suckering Hazelnut (Corylus avellana L.). Bulg. J. Agric. Sci., 21: 355357Ughini ve Roversi 2005

Srivastava, K.K., Singh, S.R., Zargar, K.A., Sundouri, A.S. 2010. Response of propagating materials and rooting hormones on rooting potential of Hazelnut (Corylus colurna L.). Indian Journal of Forestry 33(1):85-88.

TÜİK, 2016. Tarımsal üretim istatistikleri, www.tuik.gov.tr (Erişim tarihi: 26/12/2019)

Yu, X., Reed, B.M. 1995. A micropropagation system for Hazelnut (Corylus species). HortScience 30: 120123.

Yu, X.L., Reed, B.M., 1995. A micropropagation system for hazelnut (Corylus species). HortScience 30, 120123. 